\title{
ESTUDIOS
}

\author{
R. Raimbault*
}

\section{La intervención del Estado en la agricultura}

La intervención del Estado en la profesión agricola: no puede ser totalitaria sino servise de cuerpos intermediarios; si es directa ha de ser limitada y respetar la iniciativa y personalidad del campesino. Debe el Estado actuar donde nadie actúa, atento siempre a las nuevas realidades que nacen; y esto con carácter eventual y supletorio; teniendo siempre como meta la promoción a largo plazo de la vida rural.

F SENCIALMENTE el papel de los productores agrícolas consiste en poner a disposición de todos los hombres los productos de calidad necesarios para su alimentación y en asegurar a las mismas familias agrícolas los medios y las condiciones de una existencia humana. Los agricultores, pues, pretenden, a través de su profesión, realizar una función a la vez económica y social. Pueden contribuir, por medio de ella, a realizar para los miembros de la profesión y para los miembros de la sociedad una condición de vida digna de la vocación final del hombre.

Cada profesión organizada busca así promover su bien común particular, pero cada profesión tiene el riesgo de hacerlo en la ignorancia, o el desconocimiento, o el desprecio del bien común. Además las profesiones no pueden ordenar, ellas solas, por sí mismas, la economía general de un país.

Nos parece necesario que una autoridad superior, el Estado, gerente del bien común general, intervenga cerca de las profesiones.

* Director del Movimiento Familiar Rural Francés. 
Esta intervención del Estado en la profesión agrícola nos va a retener nuestra atención. Vamos a recordar principios fundamentales varias veces expresados por la Iglesia, pondremos algunos ejemplos de intervenciones del Estado e indicaremos algunas orientaciones posibles.

\section{I.-RECUERDO DE ALGUNOS PRINCIPIOS}

\section{A) Necesidad de cuerpos intermediarios}

La Iglesia, expresando las condiciones normales de vida de los hombres, pide que entre ellos y el Estado, los individuos constituyan grupos intermediarios por los cuales puedan contribuir a organizarse y a establecerse en condiciones de vida en sociedad, sin ser obligados a hacer un llamamiento directo a los servicios oficiales.

Por estos grupos intermediarios, los hombres se prestan mutuos cuidados sin necesidad de estar a cargo de un poder omnipotente. Por estos grupos, las personas pueden obtener valores esenciales al hombre: la seguridad, la responsabilidad, la libertad.

En agricultura, muy especialmente, esta forma de organización revestirá muchos aspectos, pues son diversas las necesidades de las personas.

Pensamos que estos grupos naturalmente han de procurar al hombre lo que no puede obtener por sí solo, sea en el dominio del ejercicio cotidiano de la profesión, por la mutua ayuda o el equipo en común, en el dominio de la seguridad personal o familiar, o en el del desarrollo de los conocimientos y de la cultura. Es normal que aparezcan as toda clase de grupos que son otros tantos medios para responder a las necesidades profundas de los egricultores.

Los miembros y particularmente los responsables de estos grupos no han de perder de vista que todos forman parte de una misma comunidad profesional, de la que la agricultura es el nudo, y que la organización de este cuerpo profesional es un deber fundamental de naturaleza.

Pensamos además que el hombre que no es solamente un productor, ha de encontrar en otros dominios, por ejemplo en la organización familiar - en la organización comunal, una respuesta directa a un cierto número de sus necesidades $\sin$, por tanto, esperarlo todo del Estado.

\section{B) La acción directa del Estado ha de ser limitada}

La función del Estado, dictada por su naturaleza, consiste en orientar y coordinar las actividades de las personas y de los grupos de la sociedad, de la que es el gerente, para que sean realizadas las meiores condiciones de bien común de sus miembros, sin olvidar que cada nación forma parte de una comunidad humana más vasta, lo cual tiene como inmediata consecuencia el que el Estado no se sustituya, o lo menos posible, a los grupos existentes. 
No negamos de ninguna manera que el Estado ha de trazar las grandes líneas de una política global para el conjunto de las profesiones y aun indicar los objetivos deseables de una profesión determinada cuando, en una nación, tiene la importancia que tiene la agricultura: deseamos cierta orienración o planificactón. Pero, una vez definido este cuadro general, cada cuerpo profesional ha de poder organizarse lo mejor que pueda $y$ determinar, bajo su propia iniciativa, las modalidades prácticas de una acción correspondiente por una parte a las necesidades globales expresadas por el Estado y por otra parte a las capacidades de realización establecidas por los mismos profesionales.

Seria inútil y torpe para el Estado emprender acciones y realizaciones análogas a las que realizan los profesionales cuando no están en condiciones de obrar convenientemente, por ejemplo, por falta de competencia. Seguramente el Estado deberá desempeñar un papel de suplencia, pero de tal manera que tenga el cuidado de formar y de educar a las personas, las cuales lo más rápidamente posible deberán estar en condiciones de llevar por sí mismas las actividades de su profesión.

Cuando el Estado deberá poner subvenciones de capitales a disposición de una profesión, no tendrá que desinteresarse de su gestión, ciertamente, pero deberá encontrar las fómulas para que los profesionales sean también responsables de su valorización.

Conocido es a este respecto el principio de filosofía social cristiana expresado por Pio XI en la Quadragesimo anno y recordado por Juan XXIII en la Mater et Magistra, sobre la necesidad de que no haga el Estado lo que pueden hacer los particulares y sus grupos.

\section{C) El derecho de inspección del Estado es ilimitado.}

No obstante, si decimos en efecto que la acción directa del Estado ha de ser limitada, pensamos que para ayudar a los diferentes grupos a obrar en el sentido de lo que él cree ser el bien de la sociedad cuya gestión está a su cargo, su derecho es ilimitado; hay aquí una intervención del Estado que está en la línea de su función de responsable del bien general.

Es normal que el Estado, por sus representantes, concurra a que las actividades de los diversos grupos que nacen y se desarrollan sean orientados en el sentido del interés general y contribuyan por su parte a la instauración del bien común. Control de las actividades no quiere decir dirección, sino espíritu de colaboración.

El Estado, por tanto, no tiene que actuar solo, sino a través de estos diferentes grupos libremente constituidos, con ellos y por ellos.

Asi cuanto más la profesión se organizará, cuanto más variadas serán las actividades engendradas por ello, tanto más importante deberá ser el derecho de inspección del Estaado, y entendemos por derecho del Estado, su cuidado por ver estas actividades sabiamente orientadas en función del bien de la nación y armonizadas entre sí en el cuadro de una profesión organizada. 
Cada grupo, organizado por los mismos profesionales, podrá ser tentado a no ver más que el bien individual e inmediato de sus adherentes. El Estado ha de contribuir a situarlos en una perspectiva de interés general del país entero.

Que los gobiernos estén bien persuadidos de que, cuanto más perfectamente será realizado el orden jerárquico de los diversos grupos, quedando a salvo el principio de subsidiariedad, tan recordado por los Papas, tanto mayores serán la autoridad y el poder social, y más feliz y más próspero el estado de los asuntos públicos.

\section{II.-EjEMPLOS DE INTERVENCIÓN DEL ESTADO EN LA AGRICULTURA}

Antes de ver en el tercer punto de nuestra reflexión las orientaciones posibles de intervención del Estado, presentamos rápidamente algunos ejemplos tomados de Francia.

El primero está sacado de la organización de la Vulgarización Agrícola en un departamento situado en el Oeste. Desde siempre, la vulgarización de las técnicas era esencialmente el hecho de los agentes del Ministerio de la Agricultura, los cuales por reuniones de información, de campos de experimentación, de artículos técnicos en la prensa regional, despertaban progresivamente a los agricultores a los problemas nuevos planteados por el progreso científico y sus aplicaciones en la agricultura.

El sindicalismo agrícola acometió luego por sí mismo esta acción directa y diez años después, la profesión había creado unos treinta Grupos de Vulgarización y unos veinte C.E.T.A. (Centros de Estudios Técnicos Agrícolas), y los agricultores, por medio de su organización oficial, la Cámara Departamental de Agricultura, dotaban al conjunto del departamento de un cuerpo de 35 ingenieros y consejeros colocados cerca del conjunto de estos grupos.

Este desarollo importante de una actividad particular, en el cuadro de la profesión y organizada por ella misma, ha conducido a los representantes del Ministerio de la Agricultura a mirar la modificación de su papel.

Este ya no consiste más en organizar directamente la vulgarización, sino, mucho más, en ayudar a la agricultura a organizarse ella misma. Los representantes del Ministerio tienen que estar asociados a los trabajos técnicos de los mismos agricultores, y con ellos, tienen que buscar métodos que permitan interesar y hacer participar lo más posible a los agricultores. En el cuadro de un Comité oficial, tienen que traducir cerca de los responsables agrícolas, las orientaciones generales definidas por los Poderes Públicos que representan.

Así, a medida que organismos privados toman progresivamente su sitio, el sitio y el papel del Estado son diferentes, complementarios, de un orden superior.

Segundo ejemplo. En una zona desheredada en el Centro de Francia, donde encontramos agricultores sin formación y sin preparación, el Minis- 
terio ha hecho caer a uno de sus agentes que organiza un hogar de progreso. Realiza actividades de vulgarización. Poco a poco los hombres se forman. Después de cinco años, en su zona, ya existen cinco grupos de vulgarización, llevados por los agricultores. El Estado ha sido el iniciador; ha desempeñado un papel de suplencia, la organización profesional actúa, pero el Estado no se eclipsa. Tendrá que colaborar con la profesión organizada para que los grupos obren conforme al bien común, y eso, colaborando y no imponiendo.

Otro ejemplo, de otro orden, que permite comprender mejor el papel y la intervención del Estado en una profesión que se organiza. Ha habido ocasión para una nueva ley. Se trata de la creación de los «Comités Económicos Agrícolas», cuyo papel esencial consiste en definir y hacer aplicar reglas comunes para los productores por lo que toca a la armonización de las reglas de producción, de comercialización, de precios y la promoción de ventas en una región dada, o para un mismo sector de productos.

Encontramos en el proceso de la instauración de estos Comités, el papel respectivo y complementario de la profesión y del Estado.

Recordémoslo brevemente:

Algunos productores juzgan que una iniciativa es necesaria en el interés de todos. Expresan su necesidad en el cuadro de su organización profesional.

El Estado en función del bien común juzga la proposición profesional aceptable o no. Si se da la autorización, es la profesión la que procede, en un primer tiempo, a un referendum en que ha de recoger el acuerdo de los dos tercios de los productores representando la mitad de la producción comercializada o inversamente.

Una vez se obtiene este acuerdo de los agricultores, el Estado lo traduce en textos, en reglas variables para todos los productores.

La iniciativa privada es respetada, el Estado se presenta sólo para reforzar la organización que así se han dado y continuará estando presente para que la acción conducida satisfaga las exigencias del bien del país.

\section{III.-ORIENTaciones posibles de la inTERVEnCIÓN DEL Estado}

Nos limitamos a algunas observaciones.

1) El Estado ha de promover programas de expansión a largo plazo.

No hay ninguna duda de que entra en las perspectivas de los Estados de todos los países, habida cuenta de situaciones económicas dadas y de la evolución demográfica, establecer estructuras que favorezcan la expansión económica.

Pero nos parece muy importante, esencial, que en la elaboración de estos planes estén estrechamente asociados de una manera orgánica las diferentes instituciones susceptibles de concurrir a la realización de los proyectos preparados en común y que las organizaciones sean cogestoras con el Estado de organismos semipúblicos. 


\section{R. RAIMBAULT}

En la elaboración de estos planes, una de las funciones del Estado es velar por el equilibrio, la armonía entre las grandes categorías económicas para una cierta paridad entre los trabajadores de una nación.

2) Donde la iniciativa privada no se ha manifestado, la intervención del Estado es preferible a la sola acción de los capitales.

La economía de los distintos países está en estadios diferentes de evolución. Los regímenes políticos no son idénticos. La intervención del Estado se hace, pues, bajo formas diversas.

El desarrollo económico, la instauración de estructuras agrarias, la valorización del territorio, pueden tener como origen motivos y modalidades diferentes.

Nos parece peligroso, no obstante, querer rechazar a todo precio la intervención del Estado en el dominio económico. Su acción, tenido en cuenta su papel, será más desinteresada que la de las solas sociedades capitalistas que se desarrollan sin otros móviles que la fructificación de los capitales que comprometen sin un cuidado suficiente por el respeto de los hombres, por la promoción de los valores humanos.

El Estado es más desinteresado, pero también ve más lejos y más justamente puede obrar en función del porvenir. Cuanto más el país o la región está económi amente retrasada, tanto más grande es el papel de intervención inmediata del Estado. El Estado ha de tener horror al vacio y ha de preocuparse por crear valores allí donde no hay nada o poco. Ha de asociar a ello a las poblaciones por la intermediación de organismos surgidos del seno de la población, de donde la importancia de la forma de las estructuras de intervención del Estado que pueden o bloquear o favorecer la promoción de los productores.

3) El Estado ha de dejar progresivamente la responsabilidad a los que de una manera legal dan prueba de iniciativa y de autoridad.

En muchos casos, y sin duda, en la casi totalidad de los casos, pondrá a disposición de la profesión subvenciones, material, productos y técnicos.

En la totalidad de los casos, aunque la profesión no tenga necesidad de ninguna ayuda en hombres o en capitales, su papel consistirá en controlar la actividad de la profesión para que esta actividad contribuya a promover el bien común. Pero control no quiere decir dictadura, sino colaboración estrecha. De donde la importancia de prever las estructuras donde podrá elaborarse en la armonía esta colaboración. Una profesión absolutamente dejada a si misma, aun con buena voluntad, tiene el riesgo de dañar al bien general.

4) Más bien que quedarse en situaciones fijas el Estado ha de estar atento a las realidades que nacen.

El mundo, el comportamiento de las civilizaciones mismas evolucionan, se modifican, bajo la influencia de los fenómenos técnicos y económicos. 
No se pueden parar la ciencia y los nuevos descubrimientos, Las estructuras jurídicas no pueden quedar, pues, idénticas a sí mismas.

Cada día nuevo aporta su parte de iniciativa, de emancipación de las poblaciones; la legislación que no hace más que codificar lo que hace la vida, ha de adaptarse a estos hechos y situaciones nuevas, creadas por el avance de los hombres en marcha hacia su destino. Pensamos, por ejemplo, en las instituciones de la propiedad, en las estructuras agrarias, en las relaciones de la propiedad territorial de la explotación agricola, en las adaptaciones de la explotación, en los grupos de explotación.

Legislaciones nuevas han de nacer que deberán permitir la libertad, la responsabilidad personal, pero sin olvidar la solidaridad fundamental de los seres humanos.

5) El Estado ha de contribuir al reequilibrio de las actividades económicas.

Sobre todo en el cuadro de regiones o profesiones desfavorecidas. Las inversiones del Estado han de ayudar de una manera particular a los que sufren más los desequilibrios económicos.

La ayuda del Estado, para ser justa, ha de ser selectiva y esto en nombre del bien común: impuestos, créditos y regimenes sociales han de ser previstos y organizados para reducir el retraso y el desequilibrio. Esto puede conducir, a nuestro parecer, a una transferencia de la renta de los sectores favorecidos respecto de aquellos a quienes la naturaleza de su actividad no permite un idéntico nivel de vida.

La agricultura no puede ser castigada bajo pretexto de que la ciudad tiene una necesidad indispensable de sus productos.

6) El Estado no solamente tiene un papel sobre la economia, sino igualmente un papel que cumplir para con las personas.

Especialmente tiene que corregir las deficiencias consecutivas a una economía imperfecta y en una economía organizada a veces contra naturaleza.

Tiene que velar porque las riquezas producidas sean repartidas equitativamente entre las diferentes categorías de trabajadores, incluidos los asalariados.

Por otra parte, la profesión, siendo una comunidad natural y solidaria, el Estado la ha de animar a establecer una paridad entre sus miembros ricos y sus miembros pobres, las regiones ricas y las regiones pobres, los cultivos ricos y los cultivos pobres y establecer medidas en este sentido en colaboración con la profesión.

En fin, la profesión reclama una protección social comparable a las otras categorías sociales profesionales.

La posibilidad de estudios para hijos del campo, teniendo en cuenta el paro encubierto y el subempleo en explotaciones no viables.

Estas medidas sociales, cuando se trata del mundo agrícola, no se podrían tomar sin hacer un llamamiento a los otros sectores. 
El papel del Estado aparece aquí todavía: la gestión de estas medidas en unión con la profesión.

7) En fin, parece que el Estado se ha de considerar como el árbitro entre las profesiones organizadas.

El móvil de acción de las organizaciones profesionales es naturalmente la defensa del poder de compra y el interés de sus miembros. Ahora bien, a una profesión le cuesta naturalmente situarse correctamente y espontáneamente en función del bien común. Las oposiciones entre profesiones son un hecho ineludible.

Además, no sería justo que unas organizaciones, porque representan un interés más grande, una fuerza económica más poderosa, hagan prevalecer sus puntos de vista y sus opciones, con relación a sectores profesionales desfavorecidos. No sería justo que el sector agrícola quede desfavorecido bajo pretexto de que sus productos corresponden a necesidades primarias.

El Estado es necesario para subordinar al bien común a los unos y a los otros y coordinar sus acciones. Hay que establecer estructuras para realizar esta misión. Se encontrarán tanto más fácilmente cuanto las profesiones estén. mejor organizadas.

\section{CONCLUSIÓN}

La profesión ha de obrar para el bien de sus miembros, pero el bien de sus miembros consiste en obrar subordinándose al bien común.

El Estado, dada su naturaleza de gerente del bien común, tiene como función ayuđar, animar, constreñir a las profesiones a situarse en una perspectiva de bien común y tomar las medidas para ello.

Finalmente, por encima de las estructuras, las relaciones de la profesión y del Estado son relaciones de personas de una parte y otra.

En funciones diferentes, pero complementarias, estas relaciones se han de basar en la búsqueda leal del interés general, en el respeto fundamental de la persona humana. 